\title{
Delayed contrast-enhanced MRI of the coronary artery wall in patients with Takayasu's arteritis: initial experience and comparison to patients with stable coronary artery disease
}

\author{
Christopher Schneeweis $^{1 *}$, Bernhard Schnackenburg ${ }^{2}$, Alexander Berger ${ }^{1}$, Udo Schneider $^{3}$, Matthias Stuber ${ }^{4,5}$, \\ Jing Yư ${ }^{4}$, Eckart Fleck', Rolf Gebker', Sebastian Kelle ${ }^{1}$
}

From 15th Annual SCMR Scientific Sessions

Orlando, FL, USA. 2-5 February 2012

\section{Summary}

We sought to assess late gadolinium enhancement (LGE) of the coronary artery wall and ascending aorta in patients with Takayasu arteritis (TA) compared to patients with stable CAD. Our findings suggest that LGE of the coronary artery wall can be demonstrated in patients with TA and seems to be similarly pronounced as in CAD patients. The observed coronary LGE seems rather unspecific and differentiation between coronary vessel wall fibrosis and inflammation still remains unclear.

\section{Background}

Takayasu arteritis (TA) is a rare chronic inflammatory granulomatous arteritis of the aorta and its major branches. Late gadolinium enhancement (LGE) with magnetic resonance imaging (MRI) has demonstrated its value for the detection of vessel wall alterations of large arteries in TA [1]). Involvement of coronary arteries may appear in 10 to $30 \%$ in TA [2,3]. Recently, LGE of the coronary artery wall has been demonstrated in patients with coronary artery disease (CAD) [4]. The aim of this study was to assess LGE of the coronary artery wall and ascending aorta in patients with TA compared to patients with stable CAD.

\section{Methods}

We enrolled 9 patients ( 8 female, average age $46 \pm 13$ years) fulfilling the ACR criteria [5] of TA without

IInternal Medicine/Cardiology, German Heart Institute Berlin, Berlin, Germany Full list of author information is available at the end of the article known CAD. In the CAD group 9 patients participated ( 8 male, average age $65 \pm 10$ ). CAD was defined by $x$-ray angiography as the presence of stenosis $\geq 50 \%$. Studies were performed on a commercial $3 \mathrm{~T}$ whole-body $\mathrm{MR}$ imaging system (Achieva; Philips, Best, The Netherlands). A 3D inversion prepared navigator gated spoiled gradient-echo sequence $(\mathrm{TR} / \mathrm{TE}=4.3 / 1.6 \mathrm{~ms}$, flip angle $=20^{\circ}$ voxel size: $1.0 \times 1.0 \times 2.0 \mathrm{~mm} 3$ reconstructed to $0.7 \times 0.7 \times 1 \mathrm{~mm} 3$ ) was repeated $34-45$ minutes after lowdose gadolinium administration.

\section{Results}

No coronary vessel wall enhancement was observed prior to contrast in either group. Post contrast, LGE on IR scans was detected in 28 of 50 segments $(56 \%)$ seen on T2Prep in TA and in 25 of 57 segments (44\%) in CAD patients. Quantitative LGE analysis of the ascending aorta showed a significant increase of contrast-tonoise-ratio (CNR) between pre and post contrast agent administration in TA $(5.3 \pm 4.5$ vs. $13.5 \pm 5.7)$ and in CAD patients $(2.5 \pm 2.3$ vs. $4.7 \pm 2.4)$, with $\mathrm{p}=0.028$ for both groups. A highly significant difference for CNR of the aortic wall post contrast between TA and CAD patients was observed $(\mathrm{p}=0.001)$. LGE quantitative assessment of coronary artery vessel wall CNR post contrast revealed no significant difference between the two groups (CNR in TA: $6.0 \pm 2.4$, respectively $7.3 \pm 2.5$ in CAD; $\mathrm{p}=0.474$ ).

\section{Conclusions}

Our findings suggest that LGE of the coronary artery wall can be demonstrated in patients with TA and seems to be similarly pronounced as in CAD patients. 

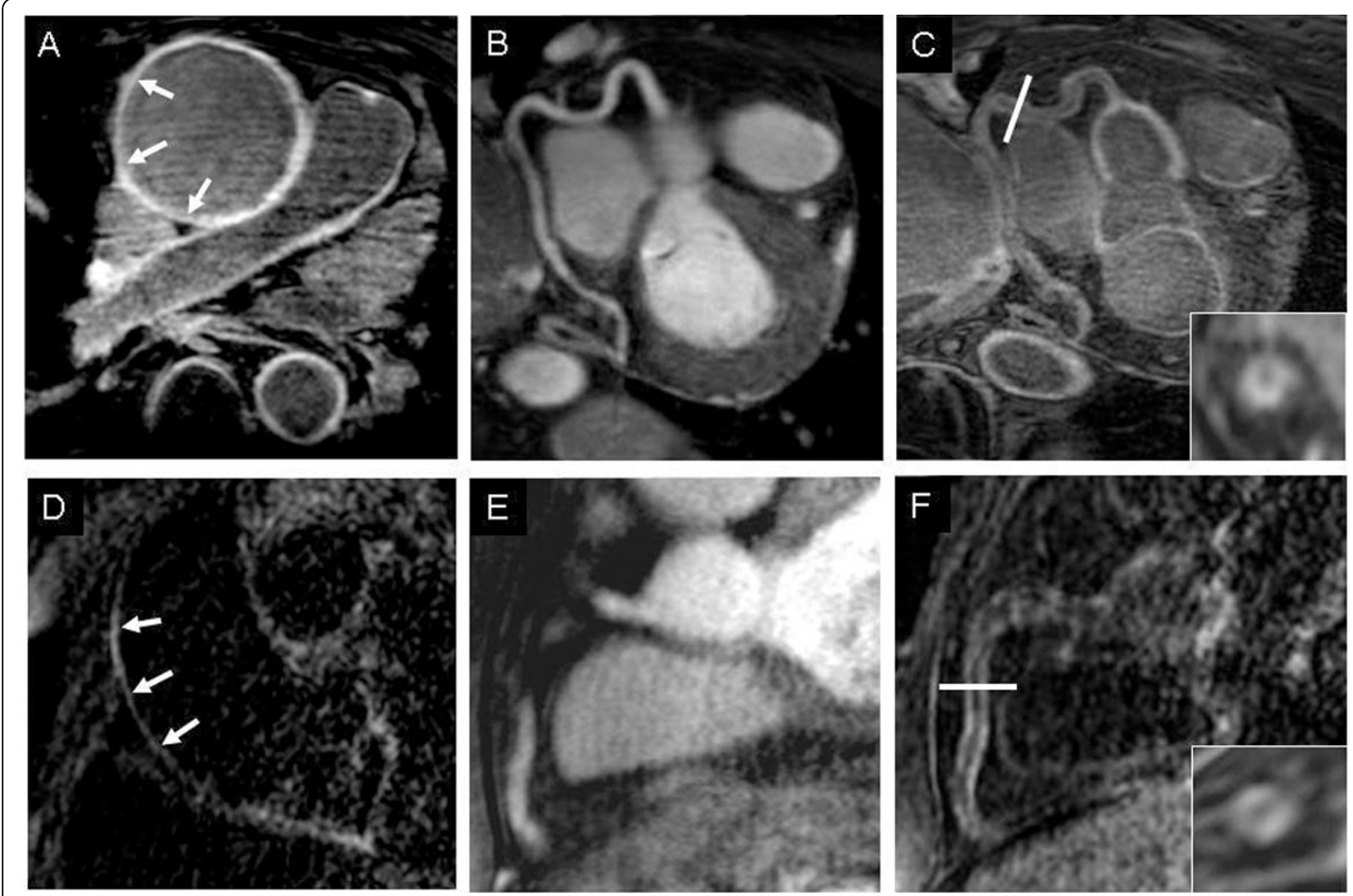

Figure 1 A shows an IR scan of the ascending aorta with LGE (white arrows) in the transverse plane in a TA patient. B demonstrates T2Prep scan of the RCA, while $C$ shows the coronary IR scan in the same patient post contrast with an enlarged cross sectional view; orientation is marked in $C$ with white bar. D shows an IR scan of the ascending aorta in the sagittal plane post contrast in a patient with CAD. In $E$, RCA of the same CAD patient in T2Prep and in F as IR scan with an enlarged cross sectional view is demonstrated.

The observed coronary LGE seems rather unspecific and differentiation between coronary vessel wall fibrosis and inflammation still remains unclear.

\section{Funding}

none.

\section{Author details}

IInternal Medicine/Cardiology, German Heart Institute Berlin, Berlin, Germany. ${ }^{2}$ Philips Health Care, Hamburg, Germany. ${ }^{3}$ Rheumatology, Charite, Berlin, Germany. ${ }^{4}$ Radiology, Johns Hopkins University, Baltimore, MD, USA

${ }^{5}$ Radiology, Center for Biomedical Imaging and University of Lausanne, Lausanne, Switzerland.

Published: 1 February 2012

\section{References}

1. Desai MY, et al: Delayed contrast-enhanced MRI of the aortic wall in Takayasu's arteritis. Am J Roentgenol 2005, 184(5):1427-1431.

2. Park MC, et al: Clinical characteristics and outcomes of Takayasu's arteritis analysis of 108 patients using standardized criteria for diagnosis, activity assessment and agiographic classification. Scand I Rheumatol 2005, 34(4):284-292

3. Rac-Acha M, et al: Coronary involvement in Takayasu's arteritis. Autoimmun Rev 2007, 6(8):566-571.
4. Kelle $S$, et al: Gadolinium enhanced MR coronary vessel wall imaging at 3,0 Tesla. Cardiol Res Pract 2010, 856418.

5. Arend WP, et al: The American College of Rheumatology 1990 criteria for the classification of Takayasu arteritis. Arthritis Rheum 1990, 33(8):1129-1134.

doi:10.1186/1532-429X-14-S1-P137

Cite this article as: Schneeweis et al:: Delayed contrast-enhanced MRI of the coronary artery wall in patients with Takayasu's arteritis: initial experience and comparison to patients with stable coronary artery disease. Journal of Cardiovascular Magnetic Resonance 2012 14(Suppl 1): P137.

\section{Submit your next manuscript to BioMed Central and take full advantage of:}

- Convenient online submission

- Thorough peer review

- No space constraints or color figure charges

- Immediate publication on acceptance

- Inclusion in PubMed, CAS, Scopus and Google Scholar

- Research which is freely available for redistribution 